\title{
Dramaturgical Capitalization of Positive Emotions: The Answer for Facebook Success?
}

\author{
Corina Sas ${ }^{1}$, Alan Dix ${ }^{1}$, Jennefer Hart ${ }^{2}$ and Ronghui Su ${ }^{1}$ \\ ${ }^{1}$ Computing Department, ${ }^{2}$ Psychology Department \\ Lancaster University, LA1 4WA, UK \\ corina@comp.lancs.ac.uk, alan@hcibook.com,j.hart@lancaster.ac.uk,r.su@lancaster.ac.uk
}

\begin{abstract}
Although user behavior in the popular Facebook social network site has been intensely investigated since the site came live in 2004, we know little about users' emotions and values weaved in the fabric of their interactions. We report on a diary study for collecting daily accounts of users' most memorable Facebook experiences. Outcomes emphasize the distinction between public and private presentation together with user motivation for engaging in these roles. Findings outline the role of impression management in the capitalization of positive emotions: a process through which people derive associated benefits from sharing them. Outcomes also suggest that at their heart, people's most memorable experiences with Facebook are all about positive emotions, in particular those concerned with connectedness and entertainment. Finally, we discuss the implications of these findings for experience design and propose design tactics and guidelines integrated into a framework for designing for connectedness and entertainment.
\end{abstract}

\section{Author Keywords}

user experience, positive emotions, Facebook social networking site, diary study, memorable experiences, experience design

\section{ACM Classification Keywords}

H5.m. Information interfaces and presentation (e.g., $\mathrm{HCI}$ ): Miscellaneous.

\section{INTRODUCTION}

The Facebook social network site is a phenomenon. With a market of over 100 million users, which is forecasted to double every six months [4], it is difficult to argue otherwise. Although younger than five years of age, the network site has already attracted researchers' interests in understanding its user behavior. Examples include usage impact on the formation and maintenance of social capital [3], adoption of third party applications [9], information revelation and privacy issues [11], usage patterns and gratifications [15], and impact of profile elements on predicting friendship links [16].

(C) The Author 2009.

Published by the British Computer Society
The dominant approach of this line of inquiry is quantitative research focused on capturing the essential elements of online behavior, either automatically or through survey methods, and applying statistical data analysis for identifying the emerging patterns. However, by narrowing the research focus on user behavior, such an approach fails to shed light into emotions, motivations and values which are particularly important in the holistic understanding of user experience [12].

We aim to address this gap by reporting on a diary-based study employed to understand the emotional aspects of Facebook use and the meaning users assign to their Facebook experiences. In this paper, we address the following research questions: what are the most memorable events experienced daily by Facebook users, what are the most often emotions associated with them, what are the meanings that people extract from their most memorable experiences, how the Facebook social interactions shape these experiences, and what design elements support them.

We believe that within the Facebook design there are powerful elements which engender memorable experiences, and that such elements can be explored and articulated as design guidelines. By understanding what constitutes a memorable experience we hope to inform the development of such guidelines. This will not only support our understanding of specific Facebook experience but can also be harnessed to enhance our understanding of experience design in general.

For this, we constructed a framework of analysis inspired by the dramaturgical theory developed by Goffman in his seminal work "Presentation of self in everyday life" [10]. Findings suggest that at their heart, people's most memorable experiences with Facebook are all about positive emotions, in particular those concerned with connectedness and entertainment. The dramaturgical theory and in particular the impression management construct shed light into how the social interactions taking place on the Facebook site facilitate the capitalization of positive emotions that Facebook users experience. Capitalization is a construct developed in the field of social psychology and refers to the process through which people derive associated benefits from sharing positive emotions.

The paper is structured in six subsequent sections. The next section summarizes previous research on social networking sites and the surprisingly limited emphasis placed on user experience. The following section 
describes the diary study in terms of procedure, sample and focus on memorable experiences. The subsequent section highlights the study findings in terms of roles that people play on the Facebook's front and back stages. Given the prevalence of positive emotions, we focused on uncovering mechanisms which allow such experiences to prevail. Thus, an entire section focuses on the process of capitalization of positive emotions and on the mechanisms which support this process. The following section discusses study implications for experience design while final remarks conclude the paper.

\section{PREVIOUS WORK}

Previous research has emphasized Facebook's role in the process of forming and managing social capital by improving self esteem and low satisfaction, and crystallizing relationships that may remain short lived [3]. Social capital refers to the collective value of a social network and can have a positive effect on interaction amongst its users [16]. Findings suggest that Facebook members use online channels less to meet new people and more to build social ties and intensify offline relationships [17]. This can be seen to improve both bonding capital in supporting tightly-knit relationships, such as close friends, as well as bridging social capital by providing a platform to maintain loose connections or "weak ties" both easily and cheaply [2][19].

Recent academic research has only touched the surface where user gratification was explored along with the relationship between profile structure and friendship articulations. Joinson [15] asked over 100 users what they enjoyed about using Facebook. Findings outline different patterns of usage, where social gratification led to increased use, whereas content gratification led to increased time on the site. In addition, social gratification along with the users profile appears to serve as an important self-presentation tool to build social capital. Lampe et al [16] suggest that profile pages that are more populated can have a positive impact to the number of friend a user has. This corresponds to common referent information, like the same college or town, which is verifiable and provides common ground that enhances interaction and reduces the cost of searching. On the other hand, preference information, i.e. likes and dislikes which are more difficult to verify are used in a more playful sense and do not have an important impact when finding new connections.

Other line of inquiry on Facebook usage has focused on the concerns of privacy and identity [11]. Such work explored the processes through which users display great trust and willingness to share personal data, despite personal profiles being able to be searchable by anyone on the same network. Joinson [15], suggest this may be linked to the ability to increase a user's social connections, providing the option to track other user's action, interests and activities. Members appear to use Facebook more as a surveillance tool for maintaining offline relationships, and to investigate people they've met offline [16]. In two surveys, over 2,000 students were investigated by Lampe et al [17]. Findings indicate that Facebook site was used mainly as a 'social searching' tool, to manage relationships initiated offline. The identified mechanisms for supporting this include maintaining contact with old friends, and getting to know new ones. This movement between online and offline frames makes Facebook distinctly different from other social networking sites, which seem to carry out more 'social browsing' or searching for new friends online with the intention of moving that relationship offline [19].

The above studies have focused predominantly on users' behavior and their pattern of usage. By capturing large volumes of data sets and extracting patterns emerging from them, they have contributed successfully to our understanding of various aspects of user behavior. However, such a quantitative approach to user research does not provide insights into the emotional experiences and values which are significant parts of user experience.

\section{STUDY}

Thirteen participants aged between 21 and 29 were recruited for the diary study. The sample consists of six female and seven male participants who were all established Facebook users, i.e. for more than 18 months. Our ethnographical approach is primarily meant to explore the relationship between the emotional aspects of user experiences and elements of Facebook design. The richness of Facebook experiences consisting of usage patterns, emotional aspects and deeply rooted values can be successfully captured by qualitative fieldwork. For this, we choose to employ a two weeks diary study followed by ethnographic interviews.

The diary was structured around the concept of most memorable experiences. This construct was investigated in the field of personality and social psychology and findings show that memorable experiences are not only emotionally charged but also saturated with personal meaning [21][22][23]. For these reasons, they are particularly suited to explore users' emotions and values one level deeper than typical experiences afford. By asking participants to record accounts of what they consider to be most memorable Facebook interactions, we left the concept of memorability open to whatever meaning participants wanted to assign to it, with the expectation that this will give us access to their deep emotional values. For probing this meaning we asked questions such as: why is this your today's most memorable experience, does the feelings you experienced matter to you, and if so, why. After the two week period, we employed ethnographic interviews with the aim to further understand the significance of these events, and the affective sense making process that took place.

We captured 103 memorable experiences, with an average of 7 entries, ranging from 4 to 15 entries per participant. Based on the insights we gained from the initial exploration of participants' records, we found useful to conceptualize the descriptions of memorable experiences in terms of symbolic expressions, stages for performance, actors, audience, communication content and emotions [14]. Although a parallel with the theater has a long history in HCI [18], a dramaturgical approach to user experience has only recently started to emerge 
particularly for exploring the orchestration of interaction with ubiquitous technologies in public places [1]. In our case, we employed the theoretical framework for dramaturgical analysis developed by Goffman [10], and borrow his relevant concepts: impression management, i.e. the act of maintaining the desired impression; symbols, i.e. sign vehicles for creating impression; back stage where self presentations are prepared and where less optimal impressions are acceptable; front stage where the performance is given; actors performing on both back stage and front stage; and audience observing the performance.

\section{FINDINGS}

Each event was categorized as capturing either a private or a public interaction, and taking place on one of the two stages, i.e. back stage or front stage respectively [20]. Furthermore, each record was identified as capturing one of the four roles: preparation for public interactions, private communication, public performance, and observation of public performance (Table 1).

\begin{tabular}{|l|l|l|l|l|}
\hline Stages & \multicolumn{2}{|c|}{ Back Stage - Private } & \multicolumn{2}{c|}{ Front Stage - Public } \\
\hline Roles & Preparation & Communication & Performance & Observation \\
\hline
\end{tabular}

\section{Table 1: The four main roles according to the stage} for performance

\section{Back Stage Role: Preparation for public interaction}

Preparation for public interaction is an activity performed privately on the back stage. In preparing for public interaction people invest effort into constructing resources for self presentation, or what Goffman called symbolic expressions for creating impression [10]. Previous work identified Facebook profiles as sign vehicles for online identity and impression management [16].

In addition, we identified other sign vehicles fabricated when people select photos to be uploaded, prepare text for status update and newsfeeds, play games alone where the scores will become public, prepare content for wallbased applications, or prepare comments on other people's photos or status. Such activities are solitary tasks but their outcomes are meant for public consumption. Not surprisingly, by engaging in this role and constructing symbols for self expression, users' emotional experiences relate mostly to feelings of satisfaction with self expression (50\%) and feelings of entertainment (33\%).

Based on the content to be captured and the intention behind creating the sign, we identified three categories of symbols which are further discussed to shed light into user's motivation for engaging in this role. Such categories capture genuine self expressions, appreciative self expression and competitive self expression.

\section{Genuine self expressions}

Genuine self expressions appear to be entirely structured around significant positive events in one's own life. In line with Goffman's construct of impression management, this can be seen as people's tendency to present themselves favorably in front of an audience [10].
Examples of significant positive events are engagement, pregnancy, new job, new partner or holidays in exotic places. Such events are quickly shared through group messages, status updates and uploaded photos, so that they can be publicly celebrated (see interview quotes).

"Message posted in the inbox, to tell us to check out her new relationship status, as she had just gotten engaged!"

"She changed her status and profile picture to let people know that she is pregnant"

"Seeing photos of a friend's new girlfriend"

"Told by a friend she's going to Hawaii..."

Besides capturing significant positive events, genuine self expressions can also reflect personal mundane events. Their role is to allow self expression while they also appear to support mood regulation.

"Updated status when I was having a difficult day. Even the act of setting my status somehow seems to help deal with stress! The ability to share little problems with the world, helps to get it off my chest. Good to be able to express myself."

"Updated status twice- once to report a problem, once to report that it was fixed! Included both a positive and negative expression Being able to share my emotions with friends Good to share problems, and feeling of happiness after the problem is fixed."

Finally, genuine self expressions consist of humorous signs about external things, people or situations which can entertain both the audience and the performer.

"He commented on a picture I posted of a car cut in half and turned into a trailer No real gain. Perhaps validation that something I found interesting was of interest to others. His comment amused me."

\section{Appreciative expressions}

Appreciative expressions consist of signs developed to express appreciation for somebody else, i.e. gratitude, congratulation or thanking. They can be elaborated expressions crafted in long hours of work.
"Things like graffiti takes time and effort, it's more personal than clicking on a button to poke someone or send them a bee. On graffiti application it would be really useful if you could save it and then carry on drawing it later. Also, it would be good if you could choose which specific graffiti you'd like to show."

\section{Competitive expressions}

Competitive expressions consist of signs developed to express humorous opinions on others' forms of self expression such as photos or status. One's motivation for developing such signs is to entertain the audience, although this may come to the expense of the person whose signs are commented upon. 
"I've commented on a picture of a friend noting the similarity of a person in the picture to Curly Watts from Corrie. I enjoy entertaining people, and the thought of making people laugh boosts self esteem."

\section{Back Stage Role: Private interactions}

In Facebook, private interactions take place between two participants on the back stage and therefore in the absence of an audience. The typical applications used for such interactions are instant messaging (IM) (70\%), email $(19 \%)$ and SMS (6\%). The analysis of users' experiences in this role, led to three groups of experiences, each of them serving a distinct role.

\section{Providing emotional support}

People engaging in private communication appear to know each other well so that they are willing to provide emotional support to each other.

\begin{abstract}
"We chatted on the instant messenger application and shared pictures through sending links. My friend is a bit unhappy and it's good to know I could help by taking her mind off things and making her laugh."
\end{abstract}

\section{Engaging in mood regulation}

Private communications are not only supportive but also warm and light-hearted. People seem to appreciate laughing and create opportunities for it.

\begin{abstract}
"We chatted for a couple of hours using the instant messaging function (text and I sent a YouTube video link). The conversation that we had made me laugh out loud. It enhances your mood to spend some time joking with friends and I find laughing and chatting very important for my state of mind."

"I sent her a message containing a YouTube link for a funny music video. It's important to have a basis of feeling that you have things in common, or things that you can share with people that you're close to."
\end{abstract}

\section{Reliving the good old times and anticipating good} times

Positive emotions in private interactions are also triggered by past positive events which are re-enacted, as well as by planning and anticipating future positive events.

"We chatted using the instant chat function. It made me remember good times that we shared in our past. I like remaining in contact with friends because it is generally easy to joke with them if you were once very close."

"We chatted using the instant messaging application and arranged to meet up soon. It made me happy to anticipate meeting up with her soon. Arranging to meet up for drinks will hopefully strengthen our friendship. It's nice to feel connected to people."

Over half of the IM-based interactions reported in the study, lasted from 30 minutes to 3 hours. These findings suggest that IM is a communication channel favored by close friends who share strong ties. For these reasons, we suggest that IM is predominantly used for strengthening strong ties. Private interactions also occur through emails $(18 \%)$ and over $70 \%$ of the interactions involving emails required less than 5 minutes. From the content analysis, emails appear to be mainly used to keep in touch with old remote friends with whom one has no longer been actively involved with, or with new friends with whom email is a more sociably accepted channel. Thus, unlike IM, emails seem to be used more for bridging rather than bonding social capital.
"Made an attempt to say hello to a few people I've not spoken to for a while. I don't like to loose touch with people, though I often seem to."
"Just contacted old friends through email because I wanted them to know that I was thinking of them."

These findings suggest that the most frequent memorable experiences taking place on the back stage are private communications through IM. They last for more than 30 minutes, provide emotional support and are experienced as feelings of connectedness (over 70\%). These aspects are indicators of strong social ties, and chat on the back stage appears to play an important role in strengthening them.

\section{Front Stage Role: Public interactions}

These forms of interactions take place between several individuals in front of an audience, which in Goffman's terms is performance on the front stage [10]. If preparation on the back stage allows people to develop symbols, now they employ such symbols to perform on a public stage. Among the Facebook applications used for public communication, wall-based ones are particularly relevant.

In this case, user experience is structured around positive emotions and ways of supporting them. This in turn makes the performers feel connected with each other $(42 \%)$ as well as entertained (39\%).

We identified that memorable events in public interactions underline strong positive experiences. Their discussion below highlights clusters of public interactions serving four distinct functions and referencing sign vehicles prepared on the back stage. While engaged in public interactions, people's predominant emotional experiences are feelings of connectedness (42\%) and entertainment (39\%).

1. Greetings and thanks for significant positive events When they are publicly shared, significant positive events generate positive emotions. Such events offer people the opportunity to relive their experience, talk about it and remember it better. Interestingly, publicly shared positive events also allow the audience to engage in feedback. A particularly relevant outcome is that in all our records of public interactions, the public feedback on positive events was positive/appreciative. 
"I found she was engaged. Loads of people post on her wall. I can see many interactions through wall to wall."

"I sent her a happy birthday message. Letting her know that I care!"

"I thanked everyone who had wished me a happy birthday, by writing on their walls. I appreciate people making the effort in friendships. It is nice to thank people for their kindness."

"He posted on my wall to thank me for a 'happy birthday' post on his wall the day before. Wasn't expecting to get a reply but it was nice of him to do so. Felt appreciated."

2. Infusing ordinary events with positive meaning Public interactions also capture personal mundane events. In this case, people appear both interested and receptive to make others feel good and to acknowledge when others make their day. In other words, people help each other to feel good to get through the day, in a way which is personally meaningful. Such process has been recognized as an active coping strategy of supporting positive affect [5].

"He wrote on my wall, left me a nice message. It's always good when your friends make you smile."

"A friend wrote on my wall, he said he hopes I enjoyed my marathon day of work! It's nice to know people think about you and make little comments to make you laugh."

"I meant to draw a graffiti on his wall. My friend has drawn me a few pictures before, and I now feel like I've finally returned the gift."

3. Exchanging tokens of affection

Not surprisingly, third party applications particularly designed to support appreciative interactions allow for positive emotions.

"She threw a strawberry at me and in response I decided to serenade her. It is just a little bit of fun. My friend is also quite special to me and I would like to think I made her happy today. It makes me happy, and I hope that my friend feels happy too."

4. Laughing with and laughing at

Almost half of the appreciative interactions engender feelings of connection. Humor accents present in such interactions are intended to make the co-performer feel better.

"He made a joke on my wall earlier so I joked on his wall, which made me laugh. It's important to laugh for mood and self esteem."

"I finally decided to get a Super Wall to see a YouTube video. It was amusing and provided light relief from working."

In contrast, humor in competitive interactions is intended to entertain the audience, sometimes to the expense of the co-performer whose picture or status are commented upon. However, only $20 \%$ of public interactions involve competitive expressions. Apart from one to one, a particular case of public interactions is group interactions which occur through group message, group chat or group play. The majority of these events are remembered as heightening the feeling of connectedness within the group $(50 \%)$.
"They sent out a text only message to all group members informing them of a new band who have agreed to play at the festival. A feeling of excitement and anticipation"
"Used our Wushu Group wall to discuss someone's return to training after they took some time off. I am glad to help people out, and see the club flourish."
"Chatted with friends whilst playing a game. It keeps me in touch with friends I don't see often."

\section{Front Stage Role: Observation of performance}

Observation of front stage performance, both in terms of public interactions and others' forms of self expression is a solitary activity taking place on the front stage. The main applications employed for this are photo browsing (67\%), monitoring status updates $(22 \%)$ as well as newsfeeds $(11 \%)$. The most prevalent emotional experience of the audience is the feeling of fun and entertainment (56\%). In addition, the diary outcomes suggest that observation of public performance could serve several functions.

\section{Searching for interesting events}

Often, the audience engages in purposeful observation with the expectation of enjoying interesting performances. People may as well experience disappointment when interesting things do not happen. In most such cases people are driven by curiosity or boredom.
"No memorable experiences - checked statuses, read newsfeeds, nothing much happening. Very little going on."
"He uploaded some new photos, which I looked at. It is nice to satisfy my curiosity about what the girlfriend looks like"
"Nothing particularly memorable today - it was a boring day!"

\section{Reliving the good old times}

Photos are also reminders of positive events and browsing them helps people identify precious memory prompts to relive their own positive experiences.
"Browsing through pictures of my old friends. Going down memory lane. It reminds me of the old times that I miss."

3. Re-experiencing others' positive events

Photos help people to engage in participative acts so that they can have a second-hand experience of others' positive events. This is an important additional emotional benefit that Facebook entails.

"I looked at my friend's birthday pictures. To see what happened because I was not there for her birthday so was nice to see what fun they had." 
Other times, the emotional experience may consist of feelings of concern, appreciation and connection with others' experiences, especially if they are close friends.

"She posted pictures of her 30th birthday party.

It was good to see her having fun and being with people she cares about as she's had a rough year."

\section{The joy of laugh}

The audience can be entertained by sign vehicles particularly engineered for this.

"Her status was amusing and made me laugh. Was nice to know how people are doing, and amusing."

"He commented on a picture I posted of a car cut in half and turned into a trailer. His comment amused me."

\section{Revealing information on the front stage}

Particular communication channels such those provided by newsfeeds allow the audience to access revealing information. Such channels allow for craves in the front stage performance through which the audience gain glimpses of what is really happening. This is a significant finding and will be later discussed.

"It was just a message between them on the newsfeed, but I found out much more in their conversations between one another than I've heard from either of them recently."

\section{Capitalization of Positive Emotions}

The prevalence of positive emotions in people's most memorable Facebook experiences is a significant outcome of this study which is worth a closer investigation. The specific emotional experiences associated with each of the above roles, suggest that such positive experiences and emotions are enriched through the simple process of sharing them and publicly providing and/or receiving feedback on them. Such process through which people derive associated benefits from sharing positive emotions has been captured by a construct already developed in the field of social psychology, and in particular the work on social sharing of positive events, i.e. events which lead to positive emotions [7]. Studies in this area found that shared celebration allows capitalization of positive emotions, which means greater positive emotions beyond those associated with the positive event itself [8]. In addition, apart from the obvious 'feeling good' factor, positive emotions have been found to broaden the scope of attention and cognition, and to contribute towards increased emotional well being [6].

Given the prevalence of positive emotions, we focused on uncovering and understanding the mechanisms which allow such experiences to prevail. This section focuses on the process of capitalization of positive emotions and on the mechanisms which support this process. Through a content analysis of user experiences and their theoretical interpretations through the lens of capitalization theory, we identified four mechanisms pertaining to capitalization of positive emotions. The first two mechanisms explain how the social aspects of interaction put in motions the capitalization process, whereas the last two mechanisms describe how the emotional capital can be harnessed to strengthen the social ties and support public expression of less positive emotions.

\section{Deriving additional benefits from sharing appreciative interactions}

The person who initiates the appreciative interaction, i.e. prepares and posts the message on somebody else's wall or sends public tokens of affection, appears to engage in this for the benefit of giving something to the other. However, if this would be the only benefit, we wondered why people prefer a public communication channel when a private channel could easily support that, without the added cost of constructing a public expression. In other words, are there any other benefits associated with such public interactions that cannot be reaped from private channels only?

This research question can be addressed through the lens of capitalization theory: people do engage in the process of publicly sharing their positive experiences because in this way they can feel even better. Such additional benefits derived from retelling the event to someone else are both intrapersonal and interpersonal. Intrapersonal benefits consist of re-experiencing the event, prolonging and enhancing the experience, as well as better remembering it. Interpersonal benefits consist of fostering positive social interactions which strengthen the relationship [7], as well as allowing people to perceive that others are pleased for them [8].

\section{Publicly validating positive events}

The feedback on positive events appears to be regulated by social norms. The good news generate a mixture of feelings but the less desirable ones are either kept secret or become shared in private communication. It is the public nature of the feedback on others' good news which helps regulating it, e.g. people chose to express publicly their most publicly acceptable feelings. This norm is enforced through public applications so that such public validation of positive events often occurs from wall to wall.

\begin{abstract}
"She's going to Hawaii, where I've been several times, so made me nostalgic and jealous."

"I feel happy for her because she has been going out with this guy for ages. I also feel surprised, but happy. I thought it's nice ... I replied on her wall straight way (soon) by news. I texted friends, talked who's the first one to going engage in our group."
\end{abstract}

\section{Strengthening weak ties}

Appreciative interactions can extend beyond strong ties, particularly when public positive events become opportunities for people in weak ties to provide public positive feedback on others' positive experiences. Birthday-related applications, which automatically 
remind people of their friends' birthdays, are particularly successful in supporting this.

"Tend to wish more people happy birthday on Facebook than by card/text. Also more likely to wish people happy birthday who I talk to less frequently and/or less likely to text them to wish them happy birthday."

Although the appreciation for a birthday wish is partly due to sender's effort of remembering it, people choose to bask in the good feelings of being celebrated rather than questioning the actors' performance.

"I had lots of birthday wishes from friends all over the world, even people I don't know. Knowing that people remember. It was nice to receive so many messages from so many people."

4. Sharing less positive emotions

Only two records of memorable experiences $(2 \%)$ reflect negative emotions. Because this is rare, we decided to look closer into them. The quotes below exemplify these experiences.

"He posted on my wall after I commented on his status, sympathizing about poor courier companies. Agreed strongly with his comment. Shared experience with a friend, sympathy for them. Yes, good to connect with friends, know they are going through similar things."

"Made a comment on his posted item. He was posting about cycling facilities in [his place] and I was making comparisons with [my town]. Posted item struck a chord with me. Staying in touch with a distant friend, sharing experiences. Nice to feel connected with friends, particularly ones I have little contact with."

These interactions show that participants expressing negative emotions on the front stage benefit from the same emotional support and mood regulation, as do the participants on the back stage. However, unlike on the back stage, communication channels for publicly expressing negative feelings are status update and posted item, to which the replies were message on the wall and comments on posted item. These choices for different applications within a sequence of interactions contradict the observed norm of response to a message through the same application through which it was received. Particularly interesting is the response on the wall which changed participant experience from frustration to entertainment. This suggests that although both status updates and wall applications are public, they are appropriated differently when it comes to emotional expression, i.e. wall is 'more public' and to be used exclusively for positive experiences and emotions (as well as diffusion through humor of less positive ones), whereas status update is 'less public', functioning instead as a bridge between the back stage and the front stage. In Goffman's terms this represents a channel for a breached performance which is disruptive on the front stage [10]. However, it can also be seen as a means to make the performance authentic, by allowing safe expression of back stage feelings on the front stage.

\section{Dramaturgical mechanisms}

Public interactions are particularly suitable for dramatic expressions and we identified several mechanisms through which people orchestrate their sign vehicles for better impression management. This section describes such mechanisms outlining also the communication channels of various applications supporting them.

\section{Creating suspense}

The announcement of an event is sometimes hinted through an interaction taking place through private communication channels.

\section{"I got message from inbox, said please check my profile. The status changed. I found she was engaged!"}

This is particular powerful since although it hides the core element it creates anticipation and prepares the audience for something exciting. The use of private channel particularly contributes to this, since it creates space for the needed delay.

\section{Creating curiosity}

The communication from wall to wall sometimes consists of a sequence of exchanges whose thread may be difficult to capture when other threads are communicated alongside. When this crevice interplays with the one created by the movement from online to offline interaction, the outcome can be powerful.

\section{"Comment refers to a (real-life) conversation we had last week, so it follows on from that and kept the conversation going."}

In this way, a single (trivial) message may make sense to the leading actors but remains obscure to the large audience, i.e. the equivalent of whispering in public.

\section{"I could say the same for you, too!:-D"}

"Very nice, conforms to 6 out of the 9 rules of haiku... :) And on to history..."

In order to create curiosity people use intriguing, ambiguous or sometimes rude status updates.

\footnotetext{
"Her status was amusing (but a bit rude so won't put it here or say her name!) and made me laugh."
}

3. Creating space for co-construction of shared experience If big positive events are often reflected in the headlines and photos, there is a surprising lack of detailed descriptions publicly available for the audience. For instance none of the entries mentioned the use of blog-based applications, i.e. the story is "in the air". This may explain the highest usage rank of photo sharing application [4]. The photos are used by the audience not only for satisfying curiosity, but also for constructing understanding and participating in absence.

"He uploaded some new photos, which I looked at. It is nice to satisfy my curiosity about what the girlfriend looks like" 
"I looked at my friend's birthday pictures. To see what happened because I was not there for her birthday so was nice to see what fun they had."

\section{DISCUSSION}

Study findings suggest that the most prevalent memorable experiences were recorded as private communications between close friends which engender feelings of connectedness. Through such experiences people give and receive emotional support, laugh out loud, relive the good old times and anticipate future memorable experiences.

The second prevalent set of memorable experiences captures those in which people present themselves to the others by using the default public applications of the Facebook site. Participants engaged in public performance experience entertainment as well as a large range of positive emotions.

Another significant theme emerging from the findings is the impact of positive events on defining memorable experiences. References to positive events and positive emotions abound in our findings, and we explained this through the concept of impression management proposed by Goffman [10]. In public situations people tend to present themselves favorably, which makes them willing to share with others their best achievements and good fortunes. Once these events are made public, people start to derive additional emotional benefits, even greater than the ones triggered by the event itself. The mere act of talking about positive experiences helps people relive, prolong and remember them, and consequently feeling even better about themselves. Findings indicate that audience's response to such events is overwhelmingly positive, which creates even more positive feelings. Not at least, such exchanges of positive experiences strengthen social ties and help emotion regulation.

\section{Framework for designing for connectedness and entertainment}

The outcomes from this study outline the role of various Facebook applications in supporting the most prevalent emotional experiences, i.e. connectedness and entertainment. Based on study findings and the dramaturgical analysis of Facebook experience, we propose a framework for designing for connectedness and entertainment (Fig. 1).

Whereas connectedness requires a safe, private place, and private communication channels; entertainment requires a public stage for performers to create dramaturgical effects and impress the audience. Despite their distinctiveness, the design elements supporting connectedness and entertainment should not be seen in isolation. We argue that the need for entertainment acts as leverage for connectedness, through the capitalization of positive emotions. Key in this process is impression management which occurs in any social setting and motivates people (i) to choose flattering symbols for self presentation, and (ii) to respond favorably to others' such symbols.

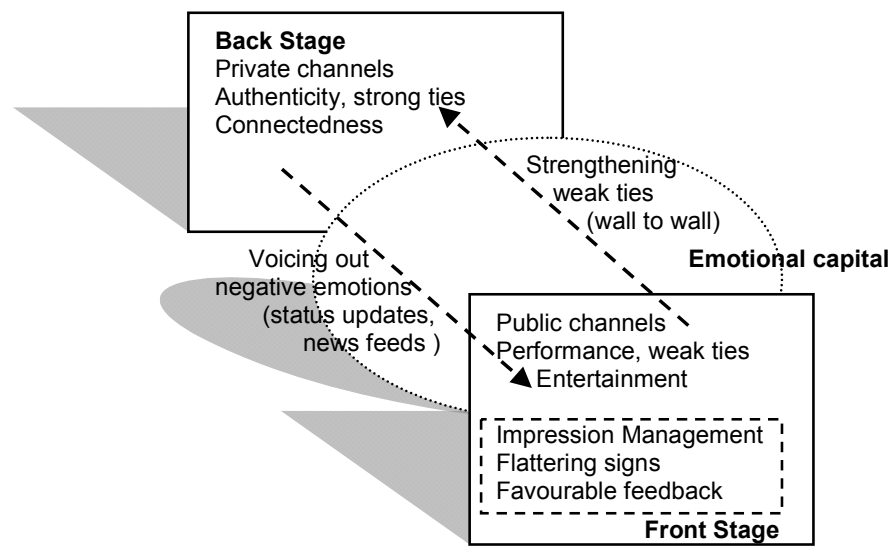

Figure 1: Framework for designing for connectedness and entertainment

\section{Designing for emotional capital}

Designing for emotional capital exploits the identified mechanisms for supporting the capitalization of positive emotions. Such mechanisms explaining how the social aspects of interaction put in motions the capitalization process are: deriving additional benefits from sharing appreciative interactions and public validation of positive events. Thus designing for emotional capital requires:

(i) offering channels for public interactions which can support dramatic expressions.

(ii) opening these channels to the audience so that it can provide feedback.

(iii) blurring the distinction between performers and audience so that the above two tactics can be fully supported, i.e. at any time, anyone can either perform or provide feedback, or even more powerful, perform and provide feedback at the same time.

\section{Designing for entertainment}

Based on the identified dramaturgical mechanisms for self expression, we propose the following design guidelines to support dramatic expression and entertainment:

(i) offering to performers both public and private channels so that people can create suspense through proper orchestration of interactions between them.

(ii) offering to the audience parts rather than whole communication both as sole exchange and within a sequence of exchanges to foster curiosity and engagement in meaning making.

(iii) offering to the audience opportunities to engage in co-construction of other's narratives based on their sign vehicles, i.e. audio-visual resources appear particularly suitable for this.

(iv) offering to performers blank spaces for written reflection, i.e. "...". Minimalist design and the metaphor of white sheet are markers for such spaces generously present in Facebook. 


\section{Designing for connectedness}

Designing for connectedness exploits capitalization of positive emotions for strengthening social ties. Our findings identified two mechanisms for this: sharing appreciative interactions and sharing less positive emotional experiences. Thus, designing for connectedness requires:

(i) offering to the audience opportunities to provide feedback on others' significant positive events. By engendering connectedness, such feedback strengthens the weak ties which in turn will move the interaction from the front stage to the back stage; birthday-based applications are perfect exemplars for this.

(ii) offering to performer communication channels for voicing out less positive emotional experiences. Although public, such channels should be perceived as safe, i.e. for instance operating under the metaphor of Hyde Park Corner. In our findings the status updates and news feeds appear to provide such bridges between back stage and front stage.

Our methodological choices served well in answering the original research questions. However, they also bear limitations. One regards the focus on the most memorable experiences. This may have led participants to record 'the best' of Facebook while avoiding less positive experiences, i.e. impression management also impacts participant-researcher interaction. Future work will look into techniques to address this gap, both at analytical level by questioning the design framework, and empirical level by asking different questions or using different probes. In addition, although a powerful tool for describing the most memorable Facebook experiences, Goffman's dramaturgical framework remains an analogy. The identified four roles represent models to explore Facebook interactions rather than means for defining them.

\section{CONCLUSION AND FUTURE WORK}

The paper describes a diary-based study aimed to investigate both the emotional aspects of Facebook use and the meaning users assign to their most memorable experiences. We employed a dramaturgical analysis of most memorable events. Study overall findings suggest that most often recorded memorable experiences occur on the back stage as private communications between close friends; and on the front stage as public communications. Findings indicate that private communications engender connectedness, while public communications offer entertainment. In this light, study outcomes suggest a shift in the balance of Facebook's role from bridging to bonding social capital. The understanding of most memorable experiences allowed us to identify the relevant elements in Facebook design supporting them. We captured these elements into several design guidelines, integrated into a framework for designing for connectedness and entertainment.

Future work will focus on developing the dramaturgical approach by applying the framework of analysis to user experiences in other social network sites. Such an analysis will allow the identification of differences and similarities both in terms of user experiences and design elements supporting the most memorable experiences. Another research direction will focus on the identified mechanisms of capturing ways in which the emotional capital is currently harnessed in the Facebook site.

The proposed design framework can also bridge the analysis of performance in social network sites with other forms of technology-based performance such as mobile and public displays experiences, or digital art live. A good understanding of the design elements which allow for capitalization of positive emotions could contribute to design guidelines for better user experience in social contexts, and not at least to the experience design in general.

\section{REFERENCES}

1. Benford, S., Crabtree, A., Reeves, S., Sheridan, J., Dix, A., Flintham, M., and Drozd, A. The Frame of the Game: Blurring the Boundary between Fiction and Reality in Mobile Experiences. In Proc. CHI 2006, ACM Press (2006), 427-436.

2. Donath, J., and boyd, d. Public displays of connection. BT Technology Journal 22, 4 (2004), 71-82.

3. Ellison, N., Steinfield, C. and Lampe, C. The benefits of Facebook "friends:" Social capital and college students' use of online social network sites. Journal of Computer-Mediated Communication 12, 4 (2007), 1143-1168.

4. Facebook Statistics. As retrieved on September 2008. http://www.new.facebook.com/press/info.php?statistic s.

5. Folkman, S. and Moskowitz, J.T. Positive affect and the other side of coping. American Psychologist 55, 6 (2000), 647-654.

6. Fredrickson, B. L. The role of positive emotions in positive psychology. American Psychologist, 6, (2001), 218-226.

7. Gable, S. L., and Reis, H. T. Appetitive and aversive social interaction. In J. Harvey and A. Wenzel (eds.), Close romantic relationships: Maintenance and enhancement (2001), 169-194. Mahwah, NJ: Erlbaum.

8. Gable, S.L., Reis, H.T., Impett, E.A., and Asher, E.R. What Do You Do When Things Go Right? The Intrapersonal and Interpersonal Benefits of Sharing Positive Events. Journal of Personality and Social Psychology 87, 2 (2004), 228-245.

9. Gjoka, M., Sirivianos, M., Markopoulou, A., Yang, X. Poking Facebook: characterization of OSN applications. In Proc. WOSP 2008, ACM Press (2008), 31-36.

10. Goffman, E. The Presentation of Self in Everyday Life. (1956). New York: Doubleday.

11. Gross, R. and Acquisti, A. Information revelation and privacy in online social networks (the Facebook case). In Proc. Privacy in the electronic society, ACM Press (2005), 71-80. 
12. Hart, J., Ridley, C., Taher, F., Sas, C., Dix, A. (2008). Exploring the Facebook Experience: A New Approach to Usability. In Proc. NordiCHI, 471-474.

13. Hochschild, A.R. Emotion Work, Feeling Rules, and Social Structure. The American Journal of Sociology, 85,3 (1979), 551-575.

14. Hunt, S.A. and Benford, R.D. Dramaturgy and Methodology', in G. Miller and R. Dingwall (eds) Context and Method in Qualitative Research, 106118. (1997). Thousand Oaks: Sage.

15. Joinson, A. N. Looking at, looking up or keeping up with people?: Motives and use of Facebook. In Proc. CHI 2008, ACM Press (2008), 1027-1036.

16. Lampe, C., Ellison, N., Steinfield, C. A familiar Face(book): profile elements as signals in an online social network. In Proc. CHI 2007, ACM Press (2007), 435-444.

17.Lampe, C., Ellison, N. and Steinfield, C. A Face(book) in the Crowd: Social Searching vs. Social Browsing, In Proc. CSCW 2006, ACM Press (2006), 167-170.
18. Laurel, B., Computer as theatre. Addison-Wesley, Reading, MA (1991).

19. Putnam R. D. Bowling alone: the collapse and revival of American community (2000) New York: Simon \& Schuster.

20. Sas, C., Dix, A., Hart. J. and Su, R. (2009). Emotional Experience on Facebook Site. In Extended Abstracts of CHI 2009, ACM Conference on Human Factors in Computing Systems.

21. Singer, J. A. Seeing one's self: Locating narrative memory in a framework of personality. Journal of Personality, 63 (1995), 429-457.

22. Thorne, A. Personal Memory Telling and Personality Development. Personality and Social Psychology Review, 4, 1 (2000), 45-56.

23. Woike, B. Most memorable experiences: Evidence for a link between implicit and explicit motives and social cognitive processes in everyday life. Journal of Personality and Social Psychology, 68(1995), 10811091. 